Jurnal Abdimas Kesehatan (JAK) Vol 4, No. 1, Januari, 2022

DOI : $10.36565 /$ jak.v4i1.172

p-ISSN: 2655-9266

e-ISSN: 2655-9218

\title{
Manfaat Hipnoterapi pada Ibu Hamil di Puskesmas Putri Ayu Kota Jambi
}

\author{
Sri Maharani \\ Program Studi DIII Kebidanan, STIKes Baiturrahim Jambi \\ Email:maharanibarus@gmail.com \\ Submitted :12/12/2020 \\ Accepted:16/10/2021 \\ Published: 28/01/2022
}

\begin{abstract}
Feelings of anxiety often accompany pregnancy, especially a mother who is mentally unstable. Anxiety reaches a climax at birth. Pain during childbirth has long been the subject of conversation among women. Therefore, many young mothers-to-be face childbirth with feelings of anxiety. Many attempts were made to overcome the anxiety problems of mothers who are about to give birth. Starting medically and various psychological therapies. One method that can be used is hypnotherapy. Hypnotherapy is an approach that is often used to deal with anxiety. The strategy used is a combination of physical relaxation and cognitive restructuring to overcome anxiety. The output target of this educational activity about the benefits of hypnotherapy for pregnant women will also be published in the form of a national scientific journal so that it can be accessed by the public. This community service activity is carried out at the Putri Ayu Health Center, Jambi City. Implementation time in July 2020. The target of this activity is pregnant women in the third trimester in the work area of the Putri Ayu Community Health Center, Jambi City. The results obtained are that pregnant women are able to understand the benefits of hypnotherapy in pregnant women. It is recommended that pregnant women participate more frequently in activities that provide knowledge for mothers by attending other health education programs so that they can increase their knowledge.
\end{abstract}

Keywords: hypnotherapy, pregnant woman

\begin{abstract}
Abstrak
Perasaan cemas seringkali menyertai kehamilan terutama seorang ibu yang labil jiwanya. Kecemasan mencapai klimaks pada saat persalinan. Rasa nyeri pada waktu persalinan sudah sejak dahulu menjadi pokok pembicaraan pada wanita. Oleh karena itu, banyak calon ibu muda menghadapi persalinan dengan perasaan cemas. Banyak upaya dilakukan untuk mengatasi masalah kecemasan para ibu yang akan melahirkan. Mulai secara medis maupun berbagai terapi psikologis. Salah satu metode yang dapat digunakan adalah hipnoterapi. Hipnoterapi merupakan sebuah pendekatan yang kerap digunakan untuk mengatasi kecemasan. Strategi yang digunakan berupa kombinasi rileksasi fisik dan merestruksturisasi kognitif untuk mengatasi kecemasan.Target luaran hasil kegiatan edukasi tentang manfaat hipnoterapi pada ibu hamilini juga akan dipublikasikan dalam bentuk jurnal ilmiah nasional sehingga dapat diakses oleh masyarakat.Kegiatan pengabdian kepada masyarakat ini dilaksanakan di Puskesmas Putri Ayu Kota Jambi. Waktu pelaksanaan pada bulan juli 2020. Sasaran dalam kegiatan ini adalah ibu hamil trimester III di wilayah kerja Puskesmas Putri Ayu Kota Jambi. Hasil yang diperoleh adalah ibu hamil mampu memahami tentang manfaat hipnoterapi pada ibu hamil. Disarankan agar ibu hamil lebih sering mengikuti kegiatan yang memberikan pengetahuan bagi ibu dengan menghadiri penyuluhan kesehatan lainnya sehingga dapat meningkatkan pengetahuan ibu.
\end{abstract}

Kata Kunci:hipnoterapi, ibu hamil 


\section{PENDAHULUAN}

Kematian ibu adalah kematian perempuan padasaat hamil atau kematian dalam kurun waktu 42 hari sejak terminasi kehamilan tanpa memandang lamanya kehamilan, yakni kematian yang disebabkan karena kehamilannya atau penanganannya, bukan karena sebab sebab lain seperti kecelakaan atau kasus insidentil. (Asmara MS, Rahayu HE, Wijayanti K, 2017)

Pada dasarnya kematian ibu disebabkan oleh dua faktor, yaitu penyebablangsung dan penyebab tidak langsung. Penyebab kematian ibu secara langsungsangat berkaitan dengan medis, berhubungan dengan komplikasi obstetric selama masa kehamilan, persalinan dan masa nifas (postpartum)seperti perdarahan, pre eklamsia dan eklamsia, partus lama, komplikasi aborsi dan infeksi. Sedangkan penyebab kematian ibu tidak langsung adalah empat terlalu dan tiga terlambat. Empat terlalu meliputi terlalu mudah hamil atau melahirkan dibawah usia20 tahun,terlalu tua usia hamil atau melahirkan di atasusia 35 tahun, terlalu dekat jarak kelahiran anak yang satu dengan yang lain di bawah tiga tahun,terlalu banyak melahirkan lebih dari tiga anak. Tiga terlambat meliputi terlambat mengambil keputusan, terlambat mengantarke tempat persalinan dan terlambat mendapat penanganan persalinan. (Asmara MS, Rahayu HE, Wijayanti K, 2017)

Dampak kecemasan yang lain menurut penelitian Muflihah (2013),meningkatkan nyeri saat persalinan, otot-otot menjadi tegang dan ibu cepat lelah, sehingga beresiko pada persalinan memanjang. Komplikasi fatal yang dapat terjadi dari hal tersebut adalah kematian ibu. Terapi nonfarmakologi yang dapat dilakukan meliputi relaksasi, guided imagery, progressive muscle relaxation, hipnoterapi dan terapi musik klasik. Hipnoterapi merupakan sebuah penyembuhan dengan hipnotis. Hipnoterapi merupakan cabang ilmu psikologis yang mempelajari manfaat sugesti untuk mengatasi masalah pikiran, perasaan, dan perilaku dengan memberikan sugestipositif kepada pikiran bawah sadar. Terapi non farmakalogi lain berdasarkan penelitianyang dilakukan oleh Analia dan Moekroni(2016), distraksi dengan mendengarkan musik merupakan teknik yang efektif untuk mengalihkan perhatian seseorang terhadap cemas berlebih..

Perasaan cemas seringkali menyertai kehamilan terutama seorang ibu yang labil jiwanya. Kecemasan mencapai klimaks pada saat persalinan. Rasa nyeri pada waktu persalinan sudah sejak dahulu menjadi pokok pembicaraan pada wanita. Oleh karena itu, banyak calon ibu muda menghadapi persalinan dengan perasaan cemas (Maramis, 2009)

Banyak upaya dilakukan untuk mengatasi masalah kecemasan para ibu yang akan melahirkan. Mulai secaramedis maupun berbagai terapi psikologis. Salah satu metode yang dapat digunakan adalah hipnoterapi. Hipnoterapi merupakan sebuah pendekatan yang kerap digunakan untuk mengatasi kecemasan. Strategi yang digunakan berupa kombinasi rileksasi fisik dan merestruksturisasi kognitif untuk mengatasi kecemasan. Seperti penanganan kecemasan dengan menggunakan disentisasi sistematis atau relaksasi otot progresif sehingga ibu hamil akan diperintahkan untuk rileks dari keluhan fisik serta mengabaikan rangsangan kecemasan.

Menurut Detiana, (2010) kehamilan merupakan peristiwa baru bagi ibu hamil pertama. Kehamilan ini akan menimbulkan perubahan-perubahan fisik maupun psikis. Perubahanperubahan ini akan menimbulkan masalah psikologi. Kehamilan sebagai peristiwa yang belum pernah dialami ini akan menimbulkan masalah psikologi diantaranya perasaan takut, gelisah, tegang bercampur 
was-was dan cemas. Kehamilan pertama yang dialami oleh ibu hamil akan menimbulkan beberapa perasaan yang bercampur aduk. Perasaan yang bercampur aduk tersebut yang sering dirasakan oleh ibu hamil pertama. persaan tersebut membentuk dinamika psikologi.

Dinamika psikologi yang dialami oleh ibu hamil petama yaitu perasaan bahagia, cemas, mudah menangis, mudah tersinggung, sering bermimpi, berkhayal dan memikirkan hal yang bukan-bukan (Detiana, 2010). Ibu hamil pertama yang mengalami kecemasan akan menimbulkan gejalagejala psikologi. Gejala-gejala psikologi inilah sebagai tanda bagi ibu yang sedang mengalami kecemasan untuk menyadari kecemasan yang dialaminya. Gejala-gejala psikologis yang muncul ketika ibu hamil yang mengalami kecemasan adalah adanya perasaan takut, khawatir, tegang, dan sulit konsentrasi (Detiana, 2010).

Self hypnosis atau hipnosis diri adalah suatu proses sederhana agar diri kita berada dalam kondisi rileks, tenang, dan terfokus guna mencapai suatu hasil atau tujuan tertentu, seperti mengurangi rasa mual, mengurangi stress, kepanikan, mengurangi berat badan. Self hypnosis dapat dilakukan saat merencanakan kehamilan dan selama hamil. Pada metode ini seorang ibu hamil yang mengalami mual dan muntah bisa mendapatkan relaksasi yang mendalam, baik secara fisik, nafas dan pikiran, sehingga ibu akan merasakan kenyamanan dalam menjalani kehamilannya(Widiastuti, 2019).

Berdasarkan fenomena diatas penulis tertarik memberikan pengetahuan mengenai hipnoterapibagi ibu hamil trimester III.

Tujuan dari kegiatan pengabdian ini yaitu memberikan penyuluhan kesehatan tentang hipnoterapipada ibu hamil trimester III kehamilan dengan harapan dapat memberikan kenyamanan pada ibu hamil selama menjalani kehamilan.
Manfaat pengabdian kepada masyarakat yang dilakukan adalah kegiatan ini memberikan pengalaman yang baik kepada ibu hamil untuk mengatasi keluhan yang terjadi akibat perubahan fisiologi yang terjadi selama kehamilan pada ibu hamil trimester III dengan hipnoterapi.

\section{TARGET DAN LUARAN}

1. Target

Target dalam kegiatan pengabdian kepada masyarakat ini adalah ibu hamil trimester III.

2. Luaran

Adapun luaran kegiatan pengabdian kepada masyarakat ini selain submit pada jurnal ilmiah, yaitu:

a. Pemahaman ibu hamil tentang hipnoterapi.

b. Serta pemberi kesadaran ibu hamil mengenai manfaat hipnoterapi selama hamil trimester III.

\section{METODE PELAKSANAAN}

Kegiatan pengabdian kepada masyarakat dilaksanakan pada bulan Juli 2020 dengan sasaran kegiatan adalah ibu hamil jumlah 10 orang.

Tahapan kegiatan Pengabdian kepada kepada masyarakat meliputi:

A. Persiapan

1. Sosialisasi: pertemuan dengan bidan penanggung jawab kelas ibu hamil.

2. Mengidentifikasi masalah.

3. Perumusan solusi: Menyampaikan rencana kegiatan kepada pihak puskesmas dengan mengurus surat izi melakkan pengabdian kepada masyarakat.

B. Pelaksanaan

1. Melakukan pretest (menggali pemahaman ibu hamil tentang hipnoterapipada ibu hamil trimester III selama kehamilan) 
2. Memberikan pendidikan kesehatan tentang pentingnya hipnoterapiselama kehamilan pada ibu hamil (pengertian, manfaat, cara melakukan, kelemahan).

3. Monitoring dan Evaluasi

\section{HASIL DAN PEMBAHASAN}

Kegiatan penyuluhan ini bertujuan agar ibu hamil mengetahui tentang manfaat hipnoterapipada ibu hamil trimester III. Pada pengabdian masyaraat ini dilakukan pendidikan kesehatan kepada ibu hamil mengenai manfaat hipnoterapi pada ibu hamil trimester III. Kegiatan penyuluhan berlangsung kurang lebih 30 menit dan terlaksana dengan tertib dan lancar serta mendapat antusia yang baik dari peserta, maupun puskesmas. Kegiatannya adalah melakukan pendidikan kesehatan berupa penyuluhan tentang manfaat hipnoterapi pada masa kehamilan meliputi pengertian, manfaat, cara melakukan, kelemahan. Ibu hamil cukup memahami dan sangat antusias dalam kegiatan ini, terbukti beberapa ibu-ibu bertanya khususnya tentang manfaat hipnoterapibagi kehamilan.

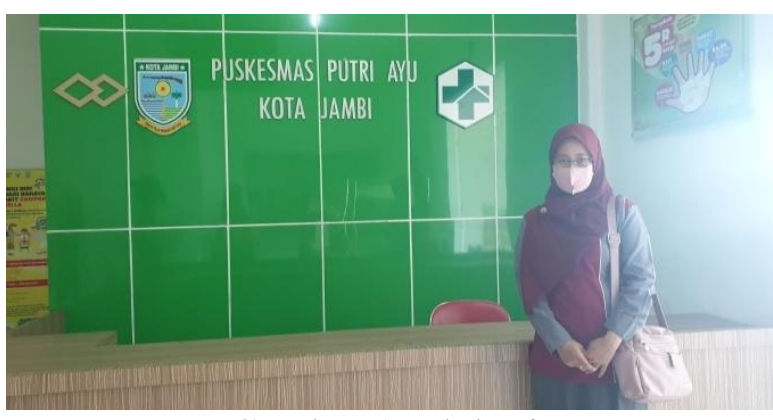

Gambar.1 Edukasi

Hipnoterapi adalah ilmu untuk mengeksplorasi pkiran, maka segala masalah yang berkaitan dengan pikiran dan perasaan biasa dibantu dengan hipnoterapi. Hipnoterapi juga bisa berperan dalam bidang kecantikan, kedokteran, kebidanan, kesehatan tubuh dan pikiran, masalah anak dan remaja, pengembangan diri, masalah seksual, bahkan untuk sekedar hiburan dan relaksasi mental.Hipnoterapi adalah aplikasi hipnosis dalam menyembuhkan gangguan mental dan meringankan gangguan fisik. Dalam praktek di lapangan hipnosis telah terbukti secara medis bisa mengatasi berbagai macam gangguan psikologis maupun fisik, misalnya menghilangkan kebiasaan buruk merokok, menghilangkan phobia (Triana, 2014).

Kecemasan adalah emosi yang tidak menyenangkan, yang ditandai dengan kekhawatiran, keprihatinan, dan rasa takut yang kadang-kadang kita alami dalam tingkat yang berbeda (Maimunah, 2011). Penyebabtimbulnya kecemasan terjadi pada ibu hamil dipengaruhi oleh beberapa faktor pengambilan keputusan, usia ibu hamil, kemampuan Ibu, kesiapan keluarga, kesehatan ibu dan pengalaman (Maimunah 2011). Dampak kecemasan pada ibu hamil dapat meningkatkan nyeri saat persalinan, otot-otot menjadi tegang dan ibu cepat lelah, sehingga beresiko pada persalinan memanjang. Komplikasi fatal yang dapat terjadi dari hal tersebut adalah kematian ibu (Muflihah, 2013). Kecemasan pada ibu hamil dapat diatasi dengan salah satu teknik nonfarmakologi yaitu hipnoterapi dan terapi musik klasik. Hipnoterapi merupakan cabang ilmu psikologis yang mempelajari manfaat sugesti untuk mengatasi masalah pikiran, perasaan, dan perilaku, dengan memberikan sugesti positif kepada pikiran bawah sadar (Elias, 2009).

Dengan metode hipnoterapi dapat membantu ibu hamil untuk memperkuat keyakinannya, bahwa akan dapat melewati persalinan dengan lancar dan tenang sesuai harapan. Latihan ini membantu ibu hamil dengan rileksasi alami untuk menurunkan ketegangan dan membantu mengatasi kecemasan mulai dari rileksasi otot dan tubuh, teknik visualisasi menghadairkan tempat yang nyaman, berkomunikasi dengan anggota tubuh dan berkomunikasi dengan 
bayi secara teratur akan membuat kondisi tubuh dan psikologis akan semakin nyaman dan membantu menurunkan rasa nyeri ketika otak telah mencapai gelombang alfa. Pada saat ini tubuh akan mengeluarkan serotonin dan endorfin sehingga ibu hamil akan berada dalam kondisi rileks tanpa kecemasan dan rasa tegang (Asmarany, 2012)

Penelitian yang dilakukan oleh (Septiarini, 2012) dengan judul penelitian "Pengaruh Hypnobirthing Terhadap Kejadian Mual Muntah Pada Ibu Hamil Trimester I Di BPS Endang Sulistyowati, S.ST, Sumberarum, Bojonegoro", di dapatkan hasil bahwa dari 10 ibu hamil trimester I yang berkunjung ke BPS, tiga ibu hamil di diantaranya mengalami mual dan muntah dan tujuh ibu hamil hanya mengalami mual saja, dengan mengikuti kelas hypnobirthing secara teratur mampu mengurangi rasa mual dan muntah yang di rasakan oleh ibu hamil.

Serta penelitian yang dilakukan oleh (Jannah, 2016), dengan judul penelitian "Pengaruh Hipnoterapi Terhadap Penurunan Derajat Cemas Serta Penurunan Frekuensi Mual Muntah Pada Ibu Hamil Primigravida Trimester I Di Puskesmas Ungaran Kabupaten Semarang", yang dilakukan dengan pengambilan sample sebanyak 38 sample yang di berikan penerapan hipnoterapi di dapatkan hasil mampu menurunkan frekuensi mual muntah pada ibu hamil.

\section{KESIMPULAN DAN SARAN}

\section{Kesimpulan}

Pelaksanaan pengabdian kepada mayarakat khususnya ibu hamil di wilayah kerja Puskesmas Putri Ayu Kota Jambi yang dilakukan oleh dosen Sekolah Tinggi Ilmu Kesehatan Baiturahim Jambi berjalan dengan baik. Ibu hamil yang hadir antusias dalam membaca leaflet yang diberikan dan bertanya apa yang mereka belum mengerti. Kegiatan ini memberikan pengalaman yang baik kepada ibu hamil untuk mengatasi keluhan yang terjadi akibat perubahan fisiologi yang terjadi selama kehamilan pada ibu hamil trimester III dengan hipnoterapi.

2. Saran

Agar lebih sering mengikuti kegiatan yang memberikan pengetahuan bagi ibu dengan menghadiri penyuluhan kesehatan lainnya sehingga dapat meningkatkan pengetahuan ibu.

\section{UCAPAN TERIMAKASIH}

Terima kasih saya ucapkan kepada STIKes Baiturrahim Jambi yang memberikan support dan memberikan pendanaan dalam pelaksanaan pengabdian masyarakat. Selain itu terima kasih pula kepada instansi tempat pelaksanan atas kerjasamanya.

\section{DAFTAR PUSTAKA}

Asmara MS, Rahayu HE, Wijayanti K. 2017. Efektifitas Hipnoterapi dan Terapi Musik Klasik terhadap Kecemasan Ibu Hamil Resiko Tinggi di Puskesmas Magelang Selatan Tahun 2017. The 6th University Research Colloquium 2017 Universitas Muhammadiyah Magelang. ISSN 2407-9189

Dewi NNAI. 2018. Peranan Hipnoterapi Untuk Mengatasi Kecemasan Menghadapi Persalinan Anak Pertama. Jurnal Psikologi "Mandala", Vol. 2, No. 2, 15-21 ISSN: 2580-4065

Widiastuti LP, Karuniadi. 2019. Pengaruh Penerapan Self-Hypnosis Terhadap Emesis Gravidarum Pada Ibu Hamil Trimester.Jurnal Ilmiah Ilmu Kesehatan: Wawasan Kesehatan, pISSN 2087-4995, e-ISSN 2598-4004. 